\title{
Intermittent right bundle branch block in a child with familial mediterranean fever
}

\author{
Özben Ceylan ${ }^{1 *}$, Yasemin Ceylan ${ }^{2 *}$ \\ ${ }^{1}$ Department of Pediatric Cardiology, Istanbul Education and Research Hospital, Istanbul, Turkey \\ ${ }^{2}$ Department of Pediatrics, Bağcılar Training and Research Hospital, Istanbul, Turkey
}

Complete right bundle branch block (RBBB) results when normal electrical activity in the HisPurkinje system is interrupted. The most common cause of RBBB is surgical closure of ventricular septal defects, especially in tetralogy of Fallot [1]. Rare cases of isolated, familial RBBB have also been reported [2].

Although a large number of intermittent left bundle branch block (LBBB) cases commonly associated with coronary heart disease have been reported in adults, a very small number of intermittent RBBB cases have been reported [3, 4]. Unlike adults, pediatric intermittent $\mathrm{RBBB}$ cases have not been reported until now. Herein, is presented the first pediatric case of intermittent RBBB in an asymptomatic 8 year old male patient with familial mediterranean fever (FMF). This is the first pediatric case in literature.

An 8-year-old boy with FMF was referred for cardiological evaluation, because of heart murmur. When he was 4 years old, he was diagnosed as having FMF according to the clinical findings and heterozygote mutation (M694V). At that time colchicine $(0.5 \mathrm{mg})$ was administered twice a day and he was completely symptom-free for 4 years. On physical examination, general condition was good and his vital signs including a blood pressure $88 / 58 \mathrm{mmHg}$, heart rate (HR) $88 \mathrm{bpm}$, respiratory rate $19 \mathrm{bpm}$ and a temperature $36.5^{\circ} \mathrm{C}$ were normal. On cardiac examination, the first heart sound and the second heart sound was normal, and no murmur was heard. Laboratory tests were as follows: white blood cell: $4.66 \times 10^{3} / \mu / \mathrm{L}$, hemoglobin: $13.2 \mathrm{~g} / \mathrm{dL}$, platelets: $191 \times 10^{3} / \mathrm{mm}^{3}$, hepatic, renal and thyroid function tests were normal. Among acute phase reactants, erythrocyte sedimentation rate (ESR) was found to be $12 \mathrm{~mm} / \mathrm{h}$ and C-reactive protein (CRP) was found to be $0.24 \mathrm{mg} / \mathrm{L}$. Serum amyloid A (SAA) $(0.1 \mathrm{mg} / \mathrm{dL})$ and troponin I $(0.00 \mathrm{ng} / \mathrm{mL})$ were all within normal limits. On electrocardiogram, it was observed that the normal QRS complexes were followed by the characteristic pattern of complete RBBB. Wide and slurred S in leads I, II, III, aVF, V4-V6, wide and slurred $R$ waves in leads aVR, $\mathrm{V} 1$, and $\mathrm{V} 2$ were observed. When the HR increased above $85 \mathrm{bpm}$, the RBBB appeared (tachycardia dependent block or acceleration-dependent block) (Fig. 1, left side A, B, C). In continuous 24-h ambulatory 3-lead Holter monitoring revealing a narrow QRS complex was observed during the night and all the following day (HR $<85 \mathrm{bpm}$ ) whereas during the HR-accelerated (HR $>85 \mathrm{bpm}$ ) period, the terminal portion of the QRS complex slurred was observed (RBBB morphology). While in the provocation test with exercise, normal QRS complex was seen at the beginning of exercise in accordance with findings in Holter, when HR increased to $85 \mathrm{bpm}$ RBBB morphology appeared (Fig. 1, right side A, B, C). Both telecardiography and echocardiography results were normal. With these findings intermittent RBBB was diagnosed and because the patient had no complaints, he was admitted to follow-up in the outpatient clinic. Intermittent RBBB persisted at 6 month follow-up.

The criteria for complete RBBB includes a QRS above the upper limit for age in combination with normal initial forces and terminal conduction

Address for correspondence: Dr. Özben Ceylan, Associate Professor, Istanbul Education and Research Hospital, Department of Pediatric Cardiology, Istanbul, Turkey, tel: +90 212 4986161, fax: +90 212 4169814, e-mail: ceylanozben@yahoo.com

Received: 21.09.2017 Accepted: 29.11.2017

*The authors had equal contribution to this work. 


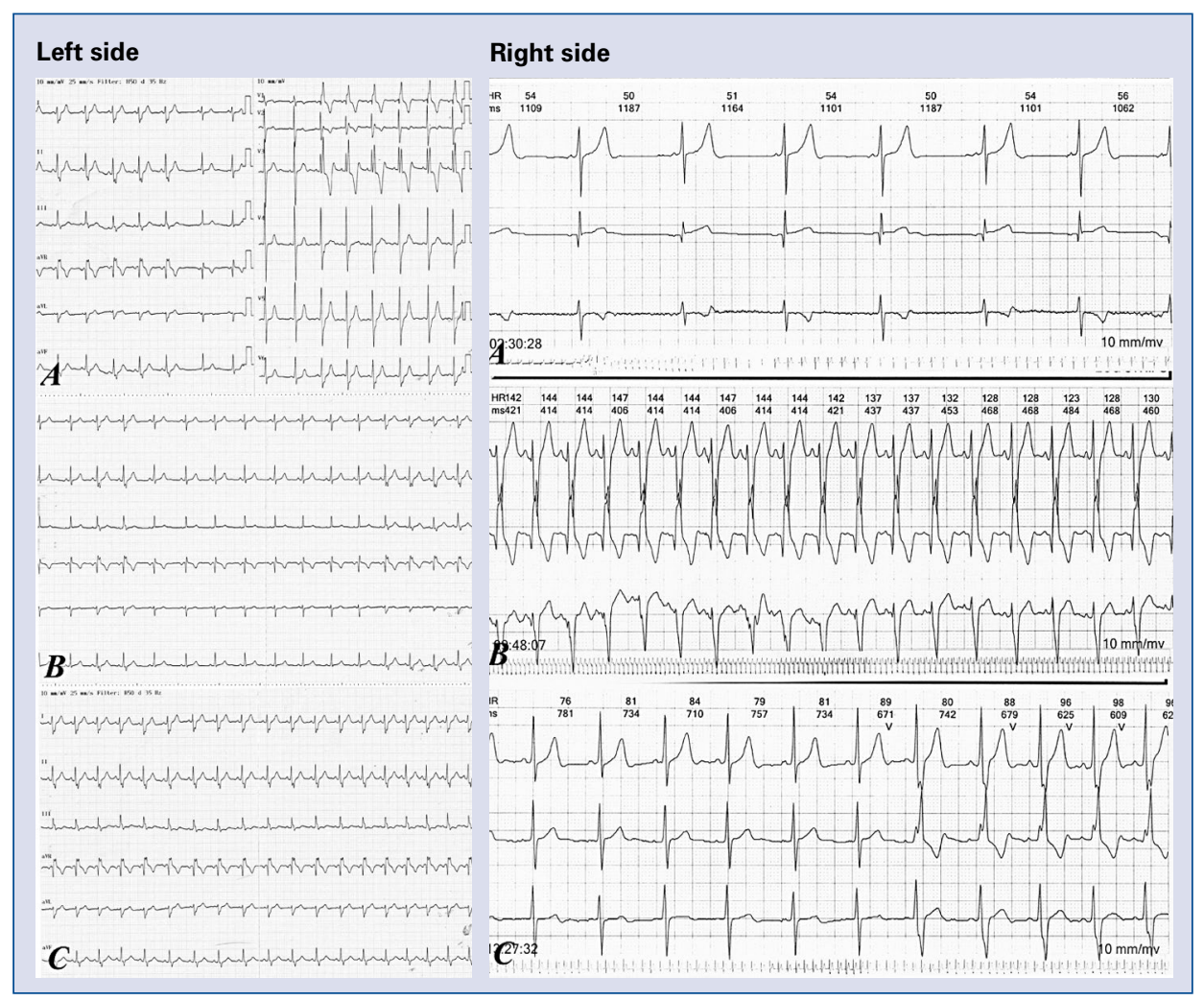

Figure 1. Left side. A. Twelve-lead electrocardiogram recording showing wide and slurred $S$ in leads I, V5, and V6; slurred R waves in leads aVR, V1, and V2; and wide and slurred S in leads II, III, and aVF (complete right bundle branch block [RBBB] findings). In extremity leads; normal conduction is seen on the 6th or 7th beat while complete RBBB conduction is seen on the 1st-5th beats. In chest leads; normal conduction is seen on first 2 beats while complete RBBB conduction is seen on the 3rd-7th beats. B. Intermittent RBBB pattern is observed. When heart rate (HR) is 85 pbm, a normal rhythm is seen, whereas when HR exceeds 85 bpm, RBBB pattern is seen (rate dependent). C. Sinus tachycardia and RBBB are seen in the provocation test made with effort. Right side. A. Continuous 24-h ambulatory 3-lead Holter monitoring revealing sinus rhythm with narrow QRS complexes at $52 \mathrm{bpm}$. B. HR at $142 \mathrm{bpm}$, is completely seen RBBB. C. While narrow QRS complexes are seen HR is below $85 \mathrm{bpm}$, RBBB pattern is observed above 85 bpm (rate dependent).

delay that is directed anteriorly, to the right and superior (wide and slurred S in leads I, V5, and V6; slurred R waves in leads aVR, V1, and V2; and wide and slurred $\mathrm{S}$ in leads II, III, and aVF) [1]. Two pediatric conditions commonly associated with RBBB are atrial septal defect and conduction disturbances after open heart surgery involving right ventriculotomy. Other congenital heart defects often associated with RBBB include Ebstein's anomaly, endocardial cushion defect, and partial anomalous pulmonary venous return; it is also occasionally seen in normal children. Rarely, RBBB is seen in myocardial diseases (cardiomyopathy, myocarditis), muscle diseases (Duchenne's muscular dystrophy, myotonic dystrophy), and Brugada syndrome [5]. There were no findings of congenital heart disease, myocardial disease, muscle disease and Brugada syndrome that would explain RBBB in our patient. The patient had a normal physical examination.
Laboratory findings acute phase reactants (ESR, $\mathrm{CRP}$ ) and SAA values were within normal limits. Also, echocardiographic findings were normal. The patient only had FMF since he was 4 years old and he had not had FMF-related attacks since he received colchicine treatment. Intermittent RBBB is thought to be related to FMF and/or colchicine, but until now RBBB associated with these conditions have not been reported.

Intermittent RBBB is formed by several mechanisms: a) phase 3 block, b) accelerationdependent block (tachycardia dependent block); c) bradycardia-dependent (phase 4) block and; d) retrograde concealment. Both acceleration-dependent and bradycardia-dependent blocks occur in diseases of the His-Purkinje system and both are abnormal [6]. In the present patient, the intermittent RBBB was due to mechanisms of the acceleration-dependent block (tachycardia dependent block). Since the 
patient had no other disease other than FMF that would affect the His-Purkinje system, it was thought that the intermittent $\mathrm{RBBB}$ had developed due to FMF. Intermittent RBBB persisted at 6 months follow up, therefore, regardless of the etiology, the His-Purkinje system is understood to have resulted in permanent damage. In autoimmune rheumatic diseases cardiac arrhythmias and conduction disturbances is seen more commonly than in the general population, but in both children and adults intermittent RBBB or other clinical arrhythmias have not been reported due to FMF, but there is a study of increased risk of arrhythmia in FMF patients $[7,8]$. Also, left ventricular function were found to be normal by conventional echocardiography, myocardial involvement has been reported with tissue Doppler and strain rate echocardiography in both adults and children with FMF and have used colchicine treatment $[9,10]$. Therefore, during the FMF attack, the right bundle branch of the His-Purkinje system may have been affected and RBBB may have developed as a result of this effect. In this case, intermittent RBBB could be a coincidental finding. However, the association of intermittent RBBB with FMF and/or colchicine cannot be excluded.

As a result, intermittent RBBB in a pediatric case was presented. The concomitant disease of FMF and the use of colchicine suggests that intermittent RBBB may develop due to FMF and/ /or colchicine. Alternatively, it can have been only founded incidentally. Therefore, patients with FMF and/or using colchicine treatment should be evaluated with electrocardiogram for detecting this possible coincidence.

Conflict of interest: None declared

\section{References}

1. Van Hare GF, Dubin AM. The Normal Electrocardiogram. In: Allen HD, Driscoll DJ, Shaddy RE, Feltes TF (ed) Moss and Adams' Heart Disease in Infants, Children, and Adolescents: Including the Fetus and Young Adults. 8th edn. Lippincott Williams and Wilkins, Philadelphia 2008: 378-379.

2. Esscher E, Hardell LI, Michaëlsson M. Familial, isolated, complete right bundle-branch block. Br Heart J. 1975; 37(7): 745-747, indexed in Pubmed: 1156482.

3. Lamb LE, Averill KH, Dermksian A, et al. Intermittent right bundle branch block without apparent heart disease. Am J Cardiol. 1959; 4: 302-313, indexed in Pubmed: 14413566.

4. Patanè S, Marte F, Sturiale M. Changing axis deviation and intermittent right bundle branch block during acute myocardial infarction. Int J Cardiol. 2011; 147(2): e26-e28, doi: 10.1016/j. ijcard.2009.01.029.

5. Park MK. Electrocardiography. In: Park MK (ed) Park: Pediatric Cardiology for Practitioners, 5th edn. Mosby and Elsevier, Philadelphia 2008: 57-58.

6. Josephson ME. Intraventricular conduction disturbances. In: Clinical cardiac electrophysiology: Techniques and interpretations. 4th Ed. Lippincott Williams and Wilkins 2008: 110-139.

7. Seferović PM, Ristić AD, Maksimović R, et al. Cardiac arrhythmias and conduction disturbances in autoimmune rheumatic diseases. Rheumatology (Oxford). 2006; 45 Suppl 4: iv39-iv42, doi: 10.1093/rheumatology/kel315, indexed in Pubmed: 16980722.

8. Ahbap E, Sakaci T, Kara E, et al. Familial Mediterranean Fever is associated with abnormal ventricular repolarization indices. Rev Med Chil. 2015; 143(12): 1560-1568, doi: 10.4067/S003498872015001200009, indexed in Pubmed: 26928618.

9. Ceylan Ö, Özgür S, Örün UA, et al. Assessment of left ventricular functions with tissue Doppler, strain, and strain rate echocardiography in patients with familial Mediterranean fever. Anatol J Cardiol. 2015; 15(8): 663-668, doi: 10.5152/akd.2014.5544, indexed in Pubmed: 25550179.

10. Sari I, Arican O, Can G, et al. Assessment of aortic stiffness and ventricular functions in familial Mediterranean fever. Anatol J Cardiol. 2008; 8(4): 271-278, indexed in Pubmed: 18676303. 